\title{
REGULACIÓN DEL ARBITRAJE ENTRE INVERSIONISTAS EXTRANJEROS Y ESTADOS RECEPTORES DE INVERSIÓN EN LOS TRATADOS DE LIBRE COMERCIO E INVERSIÓN EN AMERICA LATINA: el caso del TLC entre Peru y Estados Unidos de Norteamérica
}

\author{
REGULATION TO THE ARBITRATION BETWEEN FOREIGN INVERTONS AND INVESTMENT \\ RECEIVER STATES IN THE FREE TRADE AND INVESTMENT AGREEMENTS IN THE LATIN \\ AMERICA: the case of the FTA between Peru and United States of Norh America
}

\section{Christian Armando Carbajal Valenzuela ${ }^{1}$}

\begin{abstract}
Resumo:
O presente artigo é uma aproximação ao tratamento da arbitragem internacional em matéria de investimento estrangeiro pelos países latinoam'ericanos, que têm passado nos últimos anos de posturas abertamente hostís e restritivas a regimes mais liberais e promotores. Estudam-se as características dos principais instrumentos internacionais de caráter bilateral e multilateral para a proteção do investimento estrangeiro. Para isso se analisa a arbitragem especializada CIADI, desde um ponto de vista crítico, assim como os casos arbitrais nos quais têm participado países latinoamericanos. Finalmente, se estudam as principais inovações e contribuições incorporadas no capítulo de investimentos do Tratado de Livre Comércio subscrito pelo Peru e os Estados Unidos da América em relação à arbitragem internacional em matéria de investimento.
\end{abstract}

Palavras-chave: Direito Internacional. Investimento Estrangeiro. Arbitragem Internacional. Tratado de Livre Comércio. CIADI.

\begin{abstract}
Resumen:
El presente artículo es una aproximación al tratamiento del arbitraje internacional en materia de inversión extranjera por los países latinoamericanos, que han pasado en los últimos años de posturas abiertamente hostiles y restrictivas a regímenes más liberales y promotores. Se analizan las características de los principales instrumentos internacionales de carácter bilateral y multilateral para la protección de la inversión extranjera, para lo cual se estudia el arbitraje especializado CIADI, desde un punto de vista crítico, así como los casos arbitrales en los que han participado países latinoamericanos. Finalmente, se analizan las principales innovaciones y aportes contenidos en el capítulo de inversiones del Tratado de Libre Comercio suscrito por el Perú y Estados Unidos de Norteamérica en lo que se refiere al arbitraje internacional en materia de inversiones.
\end{abstract}

Palabras clave: Derecho Internacional. Inversiones Extranjeras. Arbitraje Internacional. Tratado de Libre Comercio. CIADI.

\footnotetext{
Abogado egresado de la Pontificia Universidad Católica del Perú. Master en Derecho Internacional Económico por la Universidad de Warwick, Inglaterra. Profesor de los cursos de "Derecho Comercial Internacional" y "Mecanismos Alternativos de Solución de Conflictos" en la Universidad de Lima y Universidad San Martín de Porres, en Lima, Perú. carbajal.c@pucp.edu.pe. Miembro de la Comissión de Publicación de la Revista da Faculdade de Direito da Universidade de São Paulo. El Autor fue invitado a escribir por el Editor de la Revista da Faculdade de Direito da Universidade de São Paulo.
} 


\begin{abstract}
:
This essay is an approximation to the treatment of foreign investment arbitration by Latin American countries, which have moved during the last years from attitudes openly hostiles and restrictives to more open and promoting regimes. It is analysed the characteristics of the main international bilateral and multilateral instruments for the protection of foreign investment, such as ICSID international arbitration, from a critical point of view, as well as the arbitration proceedings in which Latin American countries have participated. Finally, this essay focuses on the main novelties and contributions incorporated in the investment chapter of the Free Trade Agreement between Peru and the United States of America, related to foreign investment arbitration.
\end{abstract}

Keywords: International Law. Foreign Investment. International Arbitration. Free Trade Agreement. ICSID.

1. Introducción

El incremento en los países latinoamericanos del uso del arbitraje internacional en materia de inversiones se encuentra directamente relacionado con las reformas producidas en la región a partir de la década de los años noventa, cuyo objetivo fue la liberalización y desregulación de los mercados, la apertura al libre comercio, la atracción de capitales y la consolidación de marcos normativos nacionales e internacionales claramente promotores y protectores de la inversión extranjera.

Como parte de este proceso de reformas y como expresión del nuevo Derecho Internacional de las Inversiones, hoy en formación y en constante evolución, se han suscrito en los últimos años a nivel mundial diversos tratados de contenido económico. Actualmente existen aproximadamente 2500 Convenios Bilaterales de Promoción y Protección Recíproca de Inversiones (conocidos como BITs), un número similar de Convenios Internacionales para evitar la Doble Tributación y un número creciente de Tratados de Libre Comercio y de integración económica regional que incorporan capítulos sobre inversiones. Estos marcos normativos internacionales contemplan al arbitraje internacional como mecanismo natural para la solución de controversias entre particulares así como entre particulares y los Estados. ${ }^{2}$

\footnotetext{
2 “[...] Los Tratados de Libre Comercio (TLCs) y los Tratados Bilaterales de Promoción y Protección Recíproca de Inversiones (BITs) son dos tipos específicos de Acuerdos Internacionales de Inversiones (AIIs) que contienen reglas del Derecho Internacional de las Inversiones (DII) y reglas arbitrales sobre inversiones. Se trata entonces de un arbitraje que tiene una base jurídica especializada, ..... articulada a partir de tratados internacionales y normas de derecho interno de los respectivos países..." KUNDMULLER CAMINITI, Franz. El arbitraje en los AIIs 2005 -2006. Balance general e innovaciones. Revista Peruana de Arbitraje, Lima, n. 3, p. 213, 2006.
} 
Todo proceso de integración económica sea de carácter multilateral, regional o bilateral, debe contar con un mecanismo de solución de controversias que sea sólido, transparente y previsible, ya que es este mecanismo el que otorga confianza y seguridad a las partes en cuanto al real cumplimiento de las normas sustantivas contenidas en el Tratado o cuerpo normativo.

Asimismo, es importante mencionar que actualmente una importante fuente indirecta del Derecho Internacional de las Inversiones está constituida por los laudos arbitrales internacionales que resuelven conflictos entre inversionistas y Estados receptores de inversión. Esta jurisprudencia arbitral tiene una influencia decisiva sobre los futuros laudos arbitrales así como sobre los propios procesos de negociación y los textos finales de los nuevos Convenios Internacionales de Inversión, como veremos ha ocurrido en el caso del TLC Perú - Estados Unidos.

\section{Posición tradicional en América Latina frente al Arbitraje Internacional}

En relación al arbitraje internacional en materia de inversión extranjera, el Perú adoptó inicialmente, como todos los países latinoamericanos, posiciones restrictivas y claramente hostiles frente al arbitraje internacional, propias de épocas en que la cláusula o doctrina Calvo era incorporada en las Constituciones Políticas, exigiendo el sometimiento de estas controversias a las Cortes Judiciales nacionales. ${ }^{3}$

En el caso del Perú, la Constitución Política de 1993, actualmente en vigor, con un régimen económico y jurídico liberal, autoriza expresamente al Estado y a otras entidades de Derecho Público a resolver sus controversias con particulares ante tribunales arbitrales internacionales, constituidos en virtud de Tratados Internacionales en vigor. Esta norma constitucional es reglamentada por la Ley de Arbitraje y por las normas relativas a Inversiones Extranjeras del Perú que ratifican esta posibilidad de acudir al arbitraje internacional en materia de inversiones.

Esta transformación en la concepción de la soberanía absoluta del Estado peruano, que impedía el arbitraje internacional, en un concepto de soberanía relativa, que autoriza e inclusive promueve el arbitraje internacional, es una consecuencia natural de la

\footnotetext{
3 " [...] Tradicionalmente Latinoamérica ha sido considerada como un subcontinente hostil al arbitraje ... Esta afirmación resulta fácil de demostrar, simplemente apelando a las pobrísimas legislaciones arbitrales que nos han regido hasta hace muy pocos años y a la casi nula aceptación de tratados arbitrales universales, como son la Convención de Nueva York y la Convención sobre Arreglo de Diferencias Relativas a Inversiones entre Estados y Nacionales de otros Estados (CIADI) ... Sin embargo, a partir de la década pasada las cosas han comenzado a cambiar para bien". CANTUARIAS SALAVERRY, Fernando. Arbitraje Comercial y de las Inversiones. Lima: Universidad Peruana de Ciencias Aplicadas (UPC), 2007. p. 80.
} 
continua y mayor participación del Estado en las relaciones económicas internacionales así como de la necesidad de insertar al Perú en el mercado global.

3. Instrumentos de Derecho Internacional de carácter bilateral y multilateral que protegen las inversiones extranjeras

Es aceptado de manera general que la promoción de la inversión extranjera es un componente esencial en los procesos de desarrollo económico, especialmente en países con déficit de capital, ya que contribuye al crecimiento de la economía y del empleo, al desarrollo tecnológico y a la integración de la economía local a los mercados internacionales. ${ }^{4}$ Es sobre la base de esta premisa que los gobiernos de los países latinoamericanos liberalizaron en la década de los años noventa sus economías y establecieron marcos legales promotores de la inversión extranjera. El Perú no fue una excepción en esta tendencia de la región. ${ }^{5}$

El arbitraje internacional en materia de inversiones, que forma parte de este proceso de liberalización e integración a la economía mundial, ${ }^{6}$ sin duda ofrece al inversionista extranjero una serie de ventajas si comparadas con los procesos judiciales locales, como la neutralidad y la especialización de los árbitros, la celeridad, la confidencialidad y la mayor flexibilidad de los procedimientos. En una economía globalizada que se vuelve cada vez más competitiva, no es difícil constatar entonces que

4 “[...] The increase of privatization of utility and energy companies throughout Latin America, particularly in Brazil and Argentina, has attracted considerable foreign direct investment in the continent. To encourage further investment many developing countries have adopted a legal framework that complies with demands made by capital exporting states - such as the provision of a private right of action for investors against host states through international arbitration". BRUNET, Alexia; LENTINI, Juan. Arbitration of International Oil, Gas and Energy Disputes in Latin America. Northwestern Journal of International Law \& Business, Chicago, p. 593, Spring 2007.

5 “[...] En la última década, la normativa sobre arbitraje ha sido motivo de un cambio profundo en Latinoamérica. Durante este lapso de tiempo, la mayoría de las regulaciones legales se han reformado, quedando tan solo muy pocos sistemas sin adecuar sus reglas a los modernos principios que la rigen ... Por tradición, nuestro continente apegado muy profundamente al concepto de la soberanía del Estado, ha visto grandes inconvenientes en que este, o los entes que formen parte de él, se sometan al arbitraje". BERNAL GUTIÉRREZ, Rafael. El Arbitraje del Estado: la Regulación en Latinoamérica. Revista Internacional de Arbitraje, Bogota, p. 123, jun./dic. 2004.

6 “ $[\ldots]$ La protección proporcionada por los tratados solo resulta efectiva en la medida en que lo sean los mecanismos que aseguren su ejecución". BLACKABY, Nigel. El Arbitraje según los Tratados Bilaterales de Inversión y Tratados de Libre Comercio en América Latina". Revista Internacional de Arbitraje, Bogota, p. 17, jun./dic. 2004. 
el arbitraje internacional es el mecanismo de solución de controversias más utilizado en la protección de las inversiones. ${ }^{7}$

No obstante, un país determinado puede ofrecer a los inversionistas extranjeros una legislación flexible, abierta y promotora de las inversiones, pero para otorgar garantías suficientes para invertir en un país en desarrollo como los latinoamericanos, resulta necesario, adicionalmente, que el Estado se comprometa frente a la comunidad internacional a respetar y mantener invariables, durante un período de tiempo determinado, sus leyes y reglamentos internos.

En el caso del Perú, el Estado ha asumido este compromiso por medio de Convenios de Estabilidad Jurídica o Tributaria suscritos con los inversionistas extranjeros y también mediante Convenios Bilaterales de Promoción y Protección Recíproca de Inversiones (BITs). Estos convenios internacionales garantizan un marco de estabilidad y predictibilidad de la legislación aplicable a las inversiones extranjeras, incentivando la atracción y flujo de capitales, habiéndose transformado en un instrumento central del nuevo Derecho Internacional de las Inversiones.

De los cerca de 2.500 BITs suscritos en el mundo, aproximadamente 450 involucran a países de América Latina. ${ }^{8}$

El Perú ha suscrito aproximadamente 30 BITs con países como Alemania, España, Francia, Italia, Reino Unido, Suiza, Australia, China, entre otros. En América del Sur el Perú ha suscrito BITs con Argentina, Chile, Bolivia, Colombia, Paraguay, Ecuador y Venezuela, estando varios tratados en etapa de negociación.

Estos convenios incorporan principios y estándares mínimos de protección a las inversiones extranjeras, que para algunos doctrinarios forman parte de la costumbre internacional (tema controvertido), tales como las cláusulas de tratamiento justo y

\footnotetext{
7 " [...] El arbitraje como medio de solución de controversias entre inversionistas y Estados es hoy parte del estándar internacional comprendido en los Tratados de Libre Comercio (TLCs) y también en las normas de solución de controversias de los Tratados Bilaterales de Promoción y Protección Recíproca de Inversiones (TBIs). Al igual que otras instituciones jurídicas, el arbitraje en inversiones evoluciona en la medida en que avanza la producción normativa y jurisprudencial especializada en la materia”. KUNDMULLER CAMINITI, Franz. El Arbitraje y los Tratados de Libre Comercio. Revista Peruana de Arbitraje, n. 1, Lima, p. 119 , 2005.

8 “[...] Bilateral Investment Treaties (BITs) began to emerge in the late 1950s when West Germany concluded the first BIT with Pakistan. Latin American countries, began negotiating these agreements in the 1990s. Today, (almost) every Latin American country, including Cuba, has at least one BIT in force. For instance, Argentina is party to fifty-three BITs; Peru, twenty-six; Chile, thirty-six; Venezuela, twenty-one; and Ecuador, twentyone..... [...] Brazil has not yet ratified any BIT or any other investment treaty providing for international arbitration except for regional agreements relating to Mercosur". BRUNET, Alexia; LENTINI, Juan. op. cit. p. 602 and 616 .
} 
equitativo, ${ }^{9}$ tratamiento nacional, cláusula de la nación más favorecida, seguridad y protección plena a las inversiones extranjeras, compensación por pérdidas o expropiaciones, libre transferencia de activos, entre otros.

En relación a los mecanismos de solución de controversias entre inversionistas extranjeros y el Perú, los BITs suscritos por el Perú no incorporan un tratamiento uniforme. Algunos de ellos establecen el arbitraje internacional como mecanismo disponible, previa tentativa obligatoria de solución de la controversia ante las cortes judiciales locales durante un período de tiempo determinado. Otros BITs incorporan acceso directo al arbitraje internacional en la medida en que la controversia no haya sido sometida por el particular a los tribunales judiciales o administrativos locales. Otros BITs establecen vías paralelas, es decir, Corte Judicial local o Arbitraje Internacional, teniendo el inversionista el derecho de elección.

Adicionalmente a los Convenios de Estabilidad Jurídica entre el Estado y el particular y a los Convenios Bilaterales de Promoción y Protección Recíproca de Inversiones, los inversionistas extranjeros en la mayoría de los países latinoamericanos, y en particular en el Perú, cuentan con otros instrumentos internacionales que protegen la inversión. El Perú ratificó el Convenio CIADI (Centro Internacional de Arreglo de Diferencias en Materia de Inversiones del Banco Mundial), los Convenios MIGA y OPIC que son seguros internacionales contra riesgos no comerciales o políticos y también las Convenciones Multilaterales de Panamá y Nueva York sobre Reconocimiento y Ejecución de Laudos Arbitrales Internacionales, que permiten el reconocimiento y ejecución en forma casi automática de laudos extranjeros en el Perú, salvo causales de exclusión taxativamente establecidas. Finalmente, a nivel regional, la Decisión n. 291 de la Comunidad Andina sobre Inversiones Extranjeras incorpora una serie de garantías adicionales al inversionista, que son igualmente de carácter obligatorio para el Perú.

4. Casos arbitrales ante el CIADI en los que han participado países de América Latina

Como consecuencia del gran número de BITs suscritos por los países latinoamericanos durante la década de los años noventa, América Latina lidera la lista de

\footnotetext{
"[...] El trato justo y equitativo que se otorga a las inversiones extranjeras es un principio general que no tiene una definición precisa. Su significado y alcance es un asunto de interpretación en cada caso en particular. Su incorporación en los BIT puede servir para múltiples propósitos: como un elemento complementario en la interpretación de cláusulas específicas del BIT, o para llenar vacíos en este, la legislación nacional o en contratos con el Estado". VEGA, María del Carmen. Convenios Internacionales de Promoción y Protección de Inversiones. Guía Legal de Negocios. Invirtiendo en el Perú. Promperú. Lima, p. 117, 1998.
} 
países demandados ante el CIADI por inversionistas extranjeros. De un total de 219 casos de 1987 a 2005, número que sin duda ha ido en aumento, los países latinoamericanos participaban en el año 2005 como Estados demandados en 68 casos, es decir, en casi 30\% de los procesos, la mayoría de los cuales relacionados con los sectores minero y energético. Argentina, participando en más de 40 casos, lideraba a lista de países demandados, debido principalmente a circunstancias producidas por la crisis económica y financiera de los años 2001 y 2002, lo que originó controversias con diversos inversionistas extranjeros en ese país. ${ }^{10}$ Igualmente participan en diversos procesos arbitrales ante el CIADI como Estados demandados, Ecuador, Perú, Chile y Venezuela, entre otros.

Aparentemente, los Estados latinoamericanos cuando ratificaron un gran número de BITs durante los años noventa, no calcularon adecuamente la magnitud de las implicaciones económicas que se derivarían de las obligaciones internacionales asumidas mediante estos Convenios Bilaterales de Promoción y Protección Recíproca de Inversión Extranjera, así como de los laudos resultantes.

El Perú, a diferencia de Argentina, por el momento ha participado como Estado demandado ante el CIADI solamente en 4 casos, relativos a inversiones extranjeras en los sectores de minería, energía, industria alimenticia y pesca. Algunos de los casos están referidos también a Convenios de Estabilidad Jurídica y Tributaria suscritos por el Estado peruano. Los inversionistas demandantes son de nacionalidad francesa, chilena, norteamericana y china. No-obstante, con el Tratado de Libre Comercio que será ratificado próximamente por Estados Unidos de Norteamérica y con el Tratado de Libre Comercio que el Perú negociará próximamente con la Unión Europea, entre otros, es muy probable que se incrementen los casos ante el CIADI en los que el Perú participe, especialmente en los sectores de recursos naturales, servicios públicos e infraestructura.

\footnotetext{
${ }^{10}$ En relación a este punto, debe tenerse en consideración la siguiente opinión en sí misma controvertida: “[...] Las demandas interpuestas por los inversionistas extranjeros contra la República Argentina ante el Centro Internacional de Arreglo de Diferencias Relativas a Inversiones CIADI (20 demandas por más de tres mil millones de dólares y 40 reclamos en etapa inicial), producto de la ejecución de las cláusulas arbitrales previstas en los Tratados Bilaterales de Protección Recíproca de Inversiones (TBI) ante la emisión de leyes de emergencia mediante las cuales se facultó principalmente al poder ejecutivo para la rescisión de los contratos públicos y la inaplicación de los factores de reajuste o indexación, rebasan, en la opinión de un amplio sector de la doctrina, la finalidad de estos tratados que era la de resolver - entre otras - cuestiones ordinarias de discriminación o expropiación indirecta, en condiciones también ordinarias y no de gran convulsión social como las acontecidas en Argentina". LINARES, Mario. Inversión Extranjera, Contratos Públicos y Arbitraje Internacional. La Experiencia Argentina y su Incidencia en Latinoamérica. Revista de Derecho Yachaq, Cusco, n. 5, p. 323, 2007.
} 
5. Algunos comentarios críticos en relación al Sistema de Arbitraje Internacional en Materia de Inversiones de CIADI

El sistema de solución de controversias en materia de inversiones del CIADI sin duda es positivo y contribuye a despolitizar este tipo de conflictos internacionales, eliminando la tradicional protección diplomática que ejercían antiguamente los países exportadores de capital para proteger a sus nacionales, ofreciendo a los inversionistas y a los Estados receptores de inversión extranjera un mecanismo directo, neutral y especializado en la materia.

En este punto es importante tener en consideración que este sistema de solución de controversias es de naturaleza mixta, no es puramente privado ni puramente público, ya que existen legítimos intereses de los inversionistas extranjeros que deben ser protegidos, pero existen también legítimos intereses públicos que deben ser tutelados por los Estados receptores de inversión, tales como la protección del medio ambiente, de la salud pública, del patrimonio cultural, de los fondos públicos, entre otros. ${ }^{11}$

Es por esta razón que con el objetivo de contribuir al perfeccionamiento del sistema, es necesario mencionar que determinados laudos arbitrales del CIADI han sido objeto de críticas, debido a inconsistencias, contradicciones con otros laudos, inadecuada motivación, falta de claridad en la aplicación a la controversia del Derecho interno del Estado receptor o del Derecho Internacional, falta de un adecuado balance por los tribunales arbitrales entre la protección de los legítimos derechos de los inversionistas y las facultades regulatorias de los Estados receptores, así como por la imposibilidad (que hoy se encuentra en revisión) de pactar un recurso de apelación contra el laudo arbitral ante una segunda instancia arbitral dentro del propio CIADI. El sistema actualmente privilegia el principio de "celeridad", como si se tratase de un arbitraje de naturaleza estrictamente privada, en detrimento de los principios de "justicia" y "certeza" en la solución de la controversia. ${ }^{12}$ Por otro lado, igualmente se menciona que el sistema CIADI no garantiza la transparencia en los procesos arbitrales, ni permitía, hasta hace poco, la participación

\footnotetext{
11 “[...] las controversias relativas a Inversión Extranjera Directa (IED) no son de naturaleza puramente comercial, ya que en ellas se encuentran involucrados no solo intereses privados sino, también, importantes asuntos de interés público". CARBAJAL VALENZUELA, Christian. Responsabilidad Internacional de los Estados frente a los inversionistas extranjeros. Comentarios en torno a la debida aplicación del derecho por los Tribunales CIADI. Revista Agenda Internacional, Lima, a. X, n. 20, p. 210, 2004.

12 " [...] Debido al hecho que las controversias relativas a IED se encuentran íntimamente relacionadas con las facultades regulatorias de los Estados receptores de inversión, los principios de celeridad y finalidad, sin dejar de ser muy importantes, deben pasar a un segundo nivel y el principio de justicia sustantiva - y por lo tanto, la precisión en la aplicación del Derecho - debe prevalecer”. Ib Ibid., p. 211.
} 
de la sociedad civil, a pesar de existir en estos conflictos asuntos de interés general, siendo este un tema controvertido, dada la naturaleza privada y convencional del arbitraje.

Como respuesta a las demandas de la sociedad civil para el logro de mayor transparencia en los arbitrajes de inversión, al encontrarse involucrados intereses públicos y generales, en los últimos Tratados Internacionales de Comercio o de Inversión, se vienen incorporando una serie de modificaciones, dirigidas en algunos casos a garantizar la participación terceros en calidad de "amicus curiae", a la apertura relativa del proceso a audiencias públicas, a la publicación de los laudos, entre otras. Esto es lo que ha ocurrido, por ejemplo, en el TLC Perú - Estados Unidos, como veremos más adelante. De igual manera, estos cambios se ven reflejados en el propio Convenio CIADI así como en la jurisprudencia arbitral más reciente.

Finalmente, una crítica y válida preocupación está relacionada con el hecho que los Estados demandados, normalmente países en desarrollo, han perdido casi la totalidad de los casos ante los Tribunales CIADI, lo que podría eventualmente poner en cuestionamiento la neutralidad de estos tribunales arbitrales, ${ }^{13}$ pudiendo originar a mediano plazo una pérdida de legitimidad del sistema CIADI, legitimidad que por el contrario en estos momentos debería ser reforzada. ${ }^{14}$

6. Mecanismo de Solución de Controversias de Inversión entre Inversionistas Extranjeros y Estados Receptores de Inversión previsto en el Capitulo 10 del TLC Perú - Estados Unidos sobre inversiones

El sistema de solución de controversias Inversionista-Estado contenido en el TLC Perú-Estados Unidos es bastante completo y supera en opinión del autor muchas de las críticas que se han formulado al sistema arbitral del CIADI como consecuencia de determinados laudos arbitrales controvertidos. El Capítulo de inversiones del TLC

\footnotetext{
13 “[...] Beginning in 1990, there were an increase number of ICSID arbitrations against Latin American countries. The increasing number of cases has had a negative impact in the evolution of the arbitration of international energy and oil disputes". BRUNET, Alexia; LENTINI, Juan. Arbitration of International Oil, Gas and Energy Disputes in Latin America. Northwestern Journal of International Law \& Business, Chicago, p. 625, Spring 2007.

14 " [...] While the investment community has watched with satisfaction the spread of investment treaties and the mounting numbers of investor victories under them, these developments have met with dismay on the part of host countries and some groups within them. Many in Latin America resent the fact that these treaties give foreign nationals greater rights than locals in some contexts, and bristle at the idea that local taxpayers will be expected to foot the bill for awards rendered by international tribunals in favour of investors". FOSTER, George. Dechert LLP. Recent Setbacks for Foreign Investors in Latin America and What They Mean for the Future of Investment Treaty Arbitration in the Region. Latin American Arbitration Review, v. 1, n. 1, p. 21, aug. 2006.
} 
busca consolidar un marco jurídico que garantice y proteja la inversión y al inversionista, coadyuvando a crear un clima adecuado, estable y previsible, tanto para el inversionista extranjero como para el Estado receptor. ${ }^{15}$ A pesar de esto, existen algunos vacíos que mencionaré a continuación.

El capítulo de inversiones se aplica únicamente a las medidas (leyes, regulaciones o prácticas en general) que un Estado receptor ejecute en relación con inversionistas extranjeros y sus inversiones en el territorio del Estado receptor. Debe por lo tanto tratarse de un acto estatal en ejercicio de autoridad regulatoria, administrativa $\mathrm{u}$ otra autoridad gubernamental propia del Ius Imperium del Estado. No debe tratarse de un acto de gobierno de naturaleza estrictamente comercial (consecuencia del hasta cierto punto discutible laudo arbitral CIADI Eudoro Olguín (inversionista peruano) v.s República del Paraguay). ${ }^{16}$ Debe hacerse un análisis estructural y funcional del acto de Estado. Lo que protege el Capítulo de Inversiones del TLC son riesgos no comerciales que pudieran afectar injustificadamente la inversión (actos o medidas gubernamentales, expropiaciones directas o indirectas, conflicto armado, guerra civil, etc.). ${ }^{17}$ Las medidas de expropiación están permitidas sólo cumpliendo determinados requisitos (que se realicen por un propósito público, que no sean discriminatorias, que se ejecuten mediante el pago pronto, adecuado y efectivo de una indemnización, siguiendo el debido proceso legal).

En este punto es importante mencionar que el TLC establece expresamente que salvo circunstancias excepcionales, no constituyen expropiaciones indirectas los actos regulatorios no discriminatorios que son diseñados y aplicados para proteger objetivos legítimos de bienestar público, tales como la salud pública, la seguridad y el medio ambiente, en cuyo caso el Estado no estaría obligado a indemnizar al inversionista. La

\footnotetext{
15 “[...] Cabe destacar en este punto que, en esencia, los Tratados de Libre Comércio (TLCs) contemporáneos incorporan, en el respectivo capítulo de inversiones, la estructura jurídica transnacional propia de un Convenio Bilateral de Promoción y Protección Recíproca de Inversiones (BITs) y de los correspondientes medios de gestión de conflictos, incluyendo el arbitraje inversionista - Estado". KUNDMULLER CAMINITI, Franz. El arbitraje en los AIIs 2005 -2006. Balance general e innovaciones. Revista Peruana de Arbitraje, Lima, n. 3, p. 125, 2006.

${ }^{16}$ Laudo Arbitral CIADI N ${ }^{\circ}$ ARB/98/5 de julio de 2001 entre Eudoro Armando Olguín (inversionista peruano) v.s. República del Paraguay, en el que se señala en el punto 73 de sus considerandos y citando a otro Tribunal de Arbitraje: “... el Tribunal debe enfatizar que los acuerdos bilaterales sobre inversiones no son pólizas de seguro contra malas decisiones de negocios".

17 “[...] Tal riesgo político tiene variados componentes, siendo los más importantes: i) la incertidumbre regulatoria propia de incursionar en sistemas legales desconocidos; y, ii) los posibles déficits institucionales - o la percepción de éstos - en una cierta jurisdicción, lo cual incide en el riesgo de que el Estado huésped interfiera con el uso y goce de una inversión sin brindar remedios adecuados". SUAREZ ANZORENA, Carlos Ignacio. Acceso a la Jurisdicción Arbitral en los Tratados Bilaterales de Inversión Suscritos por el Perú: Requisitos y Particularidades. THEMIS - Revista de Derecho, n. 57, Lima, p. 149, 2007.
} 
determinación de si estamos frente a un acto regulatorio permitido o no, dependerá de un análisis caso por caso.

El concepto de inversión en el TLC es amplio y cubre todas las formas posibles de activos que un inversionista extranjero posee o controla de manera directa o indirecta en el Estado receptor (implica el compromiso de capital u otros recursos, expectativa de ganancias y asunción de riesgos). Se protege toda inversión extranjera, realizada bajo las formas permitidas por la legislación nacional del Estado receptor, desde su establecimiento, gestión, desarrollo y hasta su liquidación.

Como si se tratase de un BIT dentro del TLC, se incorporan en el capítulo de inversiones determinados principios de protección del inversionista extranjero. Se han incorporado dos estándares relativos: (i) Trato de Nación Más Favorecida, ${ }^{18}$ que no incluye mecanismos de solución de diferencias, superando lo establecido en el laudo arbitral CIADI Maffezini - inversionista argentino v.s. Reino de España) ${ }^{19}$ y (ii) Trato Nacional. ${ }^{20}$

Asimismo, incorpora el TLC un estándar absoluto: (i) Nivel Mínimo de Trato, que conforme al Derecho Internacional Consuetudinario, incluye trato justo y equitativo, protección y seguridad plenas y protección de los derechos económicos e intereses de los extranjeros (entre otros elementos incluye la obligación de no denegar justicia y el otorgamiento de garantías de protección policial).

Es importante resaltar la referencia contenida en el TLC según la cual "la determinación de una violación a cualquier otra disposición del TLC o de otro acuerdo internacional separado (que no sea el capitulo de inversiones) no implica que se haya violado el principio de trato justo y equitativo". Esta incorporación, en opinión del autor,

\footnotetext{
${ }^{18}$ En cuanto al trato de la nación más favorecida, señala el Artículo 10.4, primer párrafo, del TLC Perú-USA: "Cada Parte concederá a los inversionistas de la otra Parte un trato no menos favorable que el que conceda, en circunstancias similares, a los inversionistas de cualquier otra Parte o de un país que no sea Parte en lo referente al establecimiento, adquisición, expansión, administración, conducción, operación y venta u otra forma de disposición de inversiones en su territorio".

${ }^{19}$ Laudo Arbitral CIADI n. ARB/97/7 sobre excepciones a la jurisdicción de enero de 2000 entre Emilio Agustín Maffezini (inversionista argentino) v.s El Reino de España, en el que se indica en los considerandos 46 y 56 , respectivamente, lo siguiente: "El segundo problema principal se refiere a si puede considerarse que las disposiciones sobre solución de controversias contenidas en un tratado con un tercero están razonablemente relacionadas con el tratamiento justo y equitativo al que se aplica la cláusula de la nación más favorecida en los tratados básicos sobre comercio, navegación o inversiones y, por consiguiente, si tales disposiciones pueden considerarse como materias comprendidas en dicha cláusula..” y “.. puede concluirse que si un tratado con un tercero contiene disposiciones para la solución de controversias que sean más favorables para la protección de los derechos e intereses del inversor que aquellos del tratado básico, tales disposiciones pueden extenderse al beneficiario de la cláusula de la nación más favorecida".

${ }^{20}$ En cuanto al trato nacional, señala el Artículo 10.3, primer párrafo, del TLC Perú-USA: “Cada Parte concederá a los inversionistas de la otra Parte un trato no menos favorable que el que conceda, en circunstancias similares, a sus propios inversionistas en lo referente al establecimiento, adquisición, expansión, administración, conducción, operación y venta u otra disposición de las inversiones en su territorio".
} 
es una consecuencia del laudo CIADI arbitral Metalclad (inversionista americano) v.s. México, ${ }^{21}$ que también fue objeto de diversas críticas, algunas legítimas y otras sin mayor fundamento.

Asimismo se señala que las protecciones contenidas en el Capítulo de Inversiones no impiden que el Estado adopte medidas que resulten necesarias para que las inversiones se efectúen tomando en cuenta inquietudes en materia ambiental, siempre y cuando tales medidas sean compatibles con el capítulo de inversiones.

\subsection{Características principales del Sistema de Solución de Controversias Inversionista - Estado contenido en el TLC Perú - Estados Unidos}

Se establece una primera etapa de consultas y negociación, que puede incluir mecanismos auto-compositivos como la mediación y la conciliación.

Si no es posible llegar a una solución y siempre que hayan pasado por lo menos seis meses de ocurridos los hechos, el demandante (normalmente el inversionista) puede someter la controversia a cualquiera de los siguientes mecanismos, de manera alternativa y excluyente:

(i) Arbitraje ante el CIADI (Centro Internacional de Arreglo de Diferencias en Materia de Inversiones del Banco Mundial). El Perú es parte del Convenio CIADI desde 1993. ${ }^{22}$ Esta seguramente será la vía más utilizada.

(ii) Arbitraje Ad-Hoc de conformidad con las Reglas de Arbitraje de la Comisión de Naciones Unidas sobre el Derecho Mercantil Internacional (reglas CNUDMI- UNCITRAL); o,

(iii) Arbitraje ante cualquier otra institución arbitral (por ejemplo ante la Cámara de Comercio Internacional de París (CCI) o podría pensarse incluso en una institución arbitral nacional, si las partes así lo acuerdan).

Con la sola presentación de la solicitud de arbitraje por el demandante se entiende perfeccionado el consentimiento a arbitraje entre ambas partes. Se entiende que

\footnotetext{
${ }^{21}$ Laudo Arbitral CIADI n. ARB (AF)/97/1 de agosto de 2000 entre Metalclad Corporation (inversionista norteamericano) v.s. Estados Unidos Mexicanos, en el que el Tribunal Arbitral llega a la conclusión que México violó el principio de trato justo y equitativo a las inversiones, al haber transgredido el principio de transparencia, principio no contenido en el Capítulo de Inversiones del Tratado de Libre Comercio de América del Norte (NAFTA), que regula la relación entre los inversionistas extranjeros y los Estados receptores de inversión. Esta interpretación del Tribunal CIADI no fue compartida por la Corte de British Columbia, Canadá, ante la cual México presentó posteriormente un recurso de anulación.

${ }^{22}$ El Perú ratificó el Convenio sobre Arreglo de Diferencias Relativas a Inversiones (CIADI) mediante Resolución Legislativa n. 26.210, publicada en el Diario Oficial El Peruano el 10 de julio de 1993 y en vigencia desde el 8 de setiembre de 1993.
} 
el consentimiento del Estado receptor ya está contenido en el TLC, salvo el supuesto (iii) mencionado en el párrafo anterior, caso en el que se requiere acuerdo expreso y por escrito entre las partes.

Es importante resaltar que la solicitud de arbitraje requiere de la renuncia por escrito a iniciar o continuar cualquier otro procedimiento ante el Poder Judicial, entidad administrativa nacional o procedimiento de cualquier otra naturaleza respecto de la misma violación, a fin de evitar foros paralelos con la posibilidad de obtener fallos contradictorios. Esto es lo que se conoce como cláusula "fork on the road" o de bifurcación de caminos.

Lo que se busca con esto es evitar innecesarias duplicidades de procedimientos o que se fomente el "forum shopping” puramente especulativo por parte de los inversionistas, desalentando con esto las demandas frívolas.

Una vez transcurridos tres años desde que el demandante tuvo o debió tener conocimiento de la violación alegada no podrá acudir al arbitraje. La controversia, en este caso, muy probablemente tendrá que ser ventilada ante las cortes nacionales del Estado receptor.

El objeto del arbitraje puede estar referido a distintos marcos normativos: (i) incumplimiento de obligaciones contenidas en el propio TLC; (ii) incumplimiento de autorizaciones estatales otorgadas a la inversión; (iii) incumplimiento de un Convenio de Inversión entre el Inversionista Extranjero y el Estado receptor. ${ }^{23}$ Los Convenios de Inversión cubiertos están limitados a convenios para la explotación de recursos naturales, prestación de servicios públicos (puertos, aeropuertos, etc.) o desarrollo de infraestructura. Por otro lado, los Convenios de Estabilidad Jurídica suscritos al amparo de los Decretos Legislativos 662 y 757 de promoción a las inversiones, ${ }^{24}$ normas relativas a la promoción de inversiones en el Perú, estarán protegidos por las disposiciones del TLC, sólo en la medida en que dichos Convenios de Estabilidad formen parte de un Convenio de Inversión más amplio entre el inversionista extranjero y el Estado receptor.

${ }^{23}$ Como ejemplos de Convenios de Inversión podemos mencionar a los contratos de concesión para la explotación de recursos naturales producto de las privatizaciones, como es el caso de la minería, contratos suscritos por PeruPetro para la exploración y/o producción de hidrocarburos, convenios de estabilidad jurídica, convenios para la ejecución de grandes obras de infraestructura, entre otros, en los que normalmente se incluye una cláusula arbitral.

${ }^{24}$ Decreto Legislativo 662, Régimen de Estabilidad Jurídica a las Inversiones Extranjeras, de agosto de 1991 y Decreto Legislativo 757, Ley Marco para el Crecimiento de la Inversión Privada, de noviembre de 1991. 
6.2. Aportes del TLC Perú-Estados Unidos en relación al sistema de solución de controversias en materia de inversiones y en especial al sistema arbitral CIADI

Se han incorporado en el TLC Perú-Estados Unidos diversas modificaciones o precisiones al sistema de solución de controversias en materia de inversiones, según ha sido desarrollado por los Tribunales Arbitrales CIADI, mediante una jurisprudencia arbitral internacional que no es vinculante pero que, como se ha mencionado anteriormente, tiene un carácter referencial importante.

Se establece en el TLC que un Estado Parte no contendiente (por ejemplo Estados Unidos en una controversia entre un inversionista americano vs. el Perú) podrá presentar comunicaciones orales o escritas ante el tribunal arbitral respecto a la interpretación del TLC. Esto es muy usual en el marco de la OMC. Sin embargo, en el marco del CIADI no es usual. No obstante, pareciera que se acerca a lo que en Derecho Internacional se conoce como protección diplomática, institución hoy superada, precisamente para evitar la politización de estos conflictos.

Otra novedad respecto al CIADI es que el Tribunal Arbitral puede permitir la presentación de amicus curiae por una persona o entidad que no sea parte en la controversia, pero que puede aportar elementos de juicio importantes para la resolución del conflicto. Este es un aporte positivo del TLC por encontrarse vinculados a este tipo de controversias asuntos de interés público, siendo todo arbitraje de inversión un arbitraje de naturaleza mixta, en el que están involucrados legítimos intereses privados y públicos.

Asimismo, se abre la posibilidad que el tribunal arbitral solicite la opinión de expertos para informar por escrito sobre cuestiones de hecho relativas a asuntos ambientales, de salud, seguridad u otros asuntos de carácter científico. Esto es muy positivo pues supera las críticas formuladas a diversos laudos arbitrales del CIADI en el sentido de no otorgar debida consideración a cuestiones de interés público en los arbitrajes internacionales de inversión.

Otra novedad respecto al CIADI es que el tribunal antes de dictar el laudo, si lo solicitan las partes, deberá presentar el proyecto de laudo a las partes para sus comentarios, los mismos que serán considerados por el tribunal arbitral. Luego de ello el tribunal emitirá el laudo. Esto no cabe de haberse pactado apelación. Este derecho de revisión del laudo por las partes se ha tomado igualmente del sistema de solución de controversias de la OMC. Si bien esta revisión del proyecto de laudo busca lograr mayor transparencia en el procedimiento arbitral y que la solución sea de alguna manera consensuada, puede a la vez debilitar el carácter hetero-compositivo y adjudicativo del 
arbitraje internacional, limitando eventualmente la autonomía y la libertad de decisión de los árbitros.

Por otro lado, se menciona que las audiencias del tribunal arbitral serán abiertas al público, salvo la protección de información confidencial que pueda poner en riesgo la seguridad del Estado, entre otros supuestos. Se busca con esto garantizar la transparencia en los procesos arbitrales. Este es sin duda un aspecto positivo, aún cuándo no se condice con una característica tradicional del arbitraje (su confidencialidad, propia de los arbitrajes estrictamente privados, entre particulares). La información deberá estar a disposición del público, con excepción de aquella que por su naturaleza no deba ser divulgada.

Otra novedad respecto al sistema del CIADI se relaciona con el Derecho aplicable a la controversia. El TLC hace una interesante distinción, buscando superar las inconsistencias de determinados laudos CIADI que han generado polémica: (i) Si se trata de una violación de una disposición del TLC, la ley aplicable será el propio TLC y las normas aplicables del Derecho Internacional; (ii) Si se trata de una violación a una autorización estatal de inversión o de un Contrato de Inversión entre el inversionista y el Estado, el derecho aplicable serán las normas especificadas en la respectiva autorización o en el convenio de inversión. Si no hay normas especificadas, la ley aplicable será la legislación del Estado receptor y las normas del Derecho Internacional, según sean aplicables. Esta disposición es positiva, pues respeta la aplicación de la ley del Estado receptor si así lo han acordado las partes, a diferencia de lo que venía ocurriendo en la jurisprudencia arbitral CIADI, en donde no existía necesariamente claridad en cuanto al derecho aplicable al fondo de la controversia, existiendo incluso laudos contradictorios en lo que se refiere a la aplicación al fondo de la controversia del Derecho Internacional o del Derecho interno del Estado receptor de la inversión, especialmente en los casos en que se hubiere pactado una determinada ley aplicable al fondo de la controversia en un Contrato de Inversión entre el inversionista extranjero y el Estado receptor, existiendo asimismo una ley aplicable distinta contenida en un Convenio Bilateral de Promoción y Protección de Inversiones (BIT) entre el Estado del inversionista y el Estado receptor de la inversión. Lo que aun está por verse es cómo resolverán los tribunales arbitrales constituidos al amparo del TLC cuándo exista contradicción entre el Derecho Internacional y el Derecho Interno y cuál será la relación entre estos dos marcos normativos.

Esta regulación busca de alguna manera aclarar la discusión y distinción existente en la jurisprudencia arbitral CIADI entre "Treaty Claims" (reclamos o demandas fundadas en un Convenio Bilateral de Inversiones o BIT) y "Contract Claims" (Reclamos o demandas derivadas de Contratos de Inversión específicos entre inversionistas extranjeros 
y Estados), por lo menos en lo que se refiere al Derecho aplicable. Distinción que por cierto no es sencilla pues una misma conducta del Estado puede implicar una violación del correspondiente BIT así como del Contrato de Inversión. Por otro lado, la violación por el Estado del BIT constituye un ilícito internacional, lo que deriva en responsabilidad internacional del Estado. Lo mismo no ocurre necesariamente con la violación por el Estado de una cláusula del Contrato de Inversión suscrito con el inversionista, ya que no necesariamente un incumplimiento contractual constituye una violación generadora de responsabilidad internacional del Estado.

La discusión permanece no obstante en lo que se refiere a las cláusulas atributivas de jurisdicción contenidas en los Convenios de Inversión entre inversionistas y Estados receptores, que establezcan como juez competente al Poder Judicial del Estado receptor. ¿Podrá el inversionista desconocer esta cláusula acudiendo directamente al arbitraje internacional, en virtud de lo dispuesto en un TLC o en un BIT? ¿Perderán todo sentido las cláusulas de jurisdicción contenidas en los Contratos de Inversión entre inversionistas y Estados? Es sin duda un tema discutible, que tendrá que ser aclarado por la jurisprudencia arbitral.

Se menciona finalmente en el TLC Perú-Estados Unidos que cuando el tribunal dicte un laudo definitivo desfavorable al demandado, el tribunal podrá ordenar el pago de daños pecuniarios e intereses, así como la restitución de la propiedad del demandante y el pago de costas y honorarios a favor del demandante. ¿Qué ocurre si el laudo es desfavorable al demandante y favorable al demandado? ¿Se ordenará al demandante el pago de daños a favor del demandado (en general los Estados receptores) por demanda frívola por ejemplo? El TLC no señala nada al respecto.

\section{Conclusión}

Podemos afirmar que el Derecho Internacional de las Inversiones y en particular el arbitraje internacional en materia de inversiones, se encuentra aun en proceso de formación, lo que hace que el rol de los laudos arbitrales CIADI sea aun más importante, pues son éstos laudos, a través de ejercicios interpretativos, los que otorgan sentido y contenido a diversos principios, derechos y obligaciones mencionados con carácter general en los tratados internacionales que regulan las relaciones económicas internacionales.

Asimismo, debemos señalar en el tema de solución de controversias inversionista extranjero v.s. Estado receptor de inversión, que el TLC Perú - Estados Unidos contiene una serie de disposiciones novedosas que buscan superar de manera creativa 
diversas inconsistencias detectadas a lo largo de los últimos años en la jurisprudencia arbitral del CIADI.

Una vez que el TLC entre en vigencia, el uso del mecanismo de solución de controversias ante el CIADI pasará a ser bastante más usual y necesario de lo que ha sido hasta el momento en el Perú, lo cual indudablemente favorecerá el clima de inversiones en la relación Perú - Estados Unidos, siendo esta la tendencia general en Latino América.

No obstante lo anterior, a fin de consolidar el arbitraje internacional en materia de inversiones y evitar su eventual erosión, resulta necesario que los tribunales arbitrales reflejen un mayor equilibro en sus decisiones, protegiendo los legítimos derechos de los inversionistas cuando el marco normativo aplicable así lo señale pero al mismo tiempo salvaguardando adecuadamente los derechos regulatorios de los Estados receptores, en la medida en que el accionar de los dichos Estados se encuentre conforme con el Derecho Internacional.

Es por ello que los tribunales arbitrales CIADI, al resolver de manera equitativa y equilibrada una controversia de inversión, deben evitar que las palabras de Brunet y Lentini a continuación transcribimos se hagan realidad o se profundicen:

[... ] many governments feel that the rights and guarantees accorded to foreign investors outnumber the benefits received from their investments. The proliferation of resource nationalism ..... impedes and does not further efforts to promote international arbitration. ${ }^{25}$

Lima, Perú, septiembre de 2007.

\section{Referencias}

BERNAL GUTIÉRREZ, Rafael. El Arbitraje del Estado: La Regulación en Latinoamérica. Revista Internacional de Arbitraje, Bogota, jun./dic. 2004.

BLACKABY, Nigel. El Arbitraje según los Tratados Bilaterales de Inversión y Tratados de Libre Comércio en América Latina”. Revista Internacional de Arbitraje, Bogota, jun./dic. 2004.

BRUNET, Alexia; LENTINI, Juan. Arbitration of International Oil, Gas and Energy Disputes in Latin America. Northwestern Journal of International Law \& Business, Chicago, Spring 2007

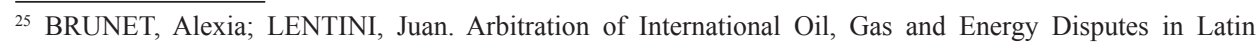
America. Northwestern Journal of International Law \& Business, Chicago, p. 625, Spring 2007. 
CANTUARIAS SALAVERRY, Fernando. Arbitraje Comercial y de las Inversiones. Universidad Peruana de Ciencias Aplicadas (UPC), Lima, Perú, 2007.

CARBAJAL VALENZUELA, Christian. Responsabilidad Internacional de los Estados frente a los inversionistas extranjeros. Comentarios en torno a la debida aplicación del derecho por los Tribunales CIADI. Revista Agenda Internacional, a. X, n. 20, Lima, 2004.

FOSTER, George. Dechert LLP. Recent Setbacks for Foreign Investors in Latin America and What They Mean for the Future of Investment Treaty Arbitration in the Region. Latin American Arbitration Review, v. 1, n. 1, aug. 2006.

KUNDMULLER CAMINITI, Franz. El Arbitraje y los Tratados de Libre Comercio. Revista Peruana de Arbitraje, Lima, n. 1, 2005.

KUNDMULLER CAMINITI, Franz. El Arbitraje en los AIIs 2005 - 2006. Balance General e Innovaciones. Revista Peruana de Arbitraje, Lima, n. 3, 2006.

KUNDMULLER CAMINITI, Franz. El Arbitraje en Inversiones en el Futuro Acuerdo de Promoción Comercial Perú - Estados Unidos. THEMIS - Revista de Derecho, Lima, n. 57, 2007.

Laudo Arbitral CIADI n. ARB/98/5 de julio de 2001 entre Eudoro Armando Olguín (inversionista peruano) v.s. República del Paraguay. En: <http://www.worldbank.org/icsid/cases/>.

Laudo Arbitral CIADI n. ARB/97/7 sobre excepciones a la jurisdicción de enero de 2000 entre Emilio Agustín Maffezini (inversionista argentino) v.s El Reino de España. En: <http://www. worldbank.org/icsid/cases>.

Laudo Arbitral CIADI n. ARB(AF)/97/1 de agosto de 2000 entre Metalclad Corporation (inversionista norteamericano) v.s. Estados Unidos Mexicanos. En: <http://www.worldbank.org/icsid/cases/>.

LINARES, Mario. Inversión Extranjera, Contratos Públicos y Arbitraje Internacional. La Experiencia Argentina y su Incidencia en Latinoamérica. Revista de Derecho Yachaq, Cusco, n. 5, 2007.

TLC Perú - Estados Unidos de Norteamérica. En: <http://www.tlcperu-eeuu.gob.pe/>.

VEGA, María del Carmen. Convenios Internacionales de Promoción y Protección de Inversiones. Guía Legal de Negocios. Invirtiendo en el Perú. Promperú. Lima, Perú, 1998.

SUAREZ ANZORENA, Carlos Ignacio. Acceso a la Jurisdicción Arbitral en los Tratados Bilaterales de Inversión Suscritos por el Perú: Requisitos y Particularidades. THEMIS - Revista de Derecho, Lima, n. 57, 2007. 